Canadian

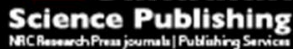

Canadian Geotechnical Journal Revue canadienne de géotechnique

\title{
Effect of Hysteresis of Soil-Water Characteristic Curves on Infiltration under Different Climatic Conditions
}

\begin{tabular}{|r|l|}
\hline Journal: & Canadian Geotechnical Journal \\
\hline Manuscript ID & cgj-2015-0004.R1 \\
\hline Manuscript Type: & Article \\
\hline Date Submitted by the Author: & $17-J u l-2015$ \\
\hline Complete List of Authors: & $\begin{array}{l}\text { Bashir, Rashid; York University, Department of Civil Engineering } \\
\text { Sharma, Jitendra; York University, Department of Civil Engineering } \\
\text { Stefaniak, Natasja; Swiss Federal Institute of Technology, Institute for } \\
\text { Environmental Engineering (IfU) }\end{array}$ \\
\hline Keyword: & $\begin{array}{l}\text { Unsaturated flow, soil-water characteristic curve, hysteresis, climatic } \\
\text { conditions, numerical modelling }\end{array}$ \\
\hline
\end{tabular}




\section{Effect of Hysteresis of Soil-Water Characteristic Curves on Infiltration under Different Climatic Conditions}

Rashid Bashir, PhD, PEng

Department of Civil Engineering, Lassonde School of Engineering, York University, Toronto, Canada

Jitendra Sharma, PhD, PEng*

Department of Civil Engineering, Lassonde School of Engineering, York University, Toronto, Canada

Halina Stefaniak

Swiss Federal Institute of Technology, Zürich, Switzerland

[* Corresponding Author; correspondence details provided below.]

\section{Correspondence Details:}

Department of Civil Engineering

356 Chemistry Building, York University - Keele Campus

4700 Keele St, Toronto ON M3J 1P3, Canada

E-mail: jit.sharma@lassonde.yorku.ca 


\section{Abstract}

2 This paper presents the results of a numerical modelling exercise to investigate the role of the

3 hysteresis of soil-water characteristic curve (SWCC) on the infiltration characteristics of soils

4 subjected to four different climatic conditions from very dry to wet within the Canadian province of

5 Alberta. Multi-year climate datasets from four different natural regions and sub-regions of Alberta

6 are compiled and classified and applied as the soil-atmosphere boundary condition in one-

7 dimensional finite element unsaturated flow models using the Hydrus-1D software. Multiyear

8 simulations are carried out with and without the consideration of SWCC hysteresis. Simulation

9 results are analyzed in terms of water balance at the ground surface and temporal distribution and

10 storage of water within the soil domain. It is demonstrated that the hysteresis of SWCC can

11 significantly affect the prediction of flow, redistribution and storage of water in the unsaturated

12 zone. It is found that for soils that exhibit hysteretic SWCC, consideration of hysteresis in

13 unsaturated flow modelling results in prediction of lower infiltration and less movement of water

14 through the soil. It is also found that the use of wetting parameters results in prediction of

15 increased infiltration and movement of water compared with the predictions using the drying or

16 hysteretic parameters. It is concluded that, for soils that exhibit greater degree of SWCC hysteresis,

17 it is important to measure both the drying and the wetting branches of the SWCC accurately and

18 that accurate simulation of hysteretic behaviour requires climate datasets at appropriate

19 resolution. The results presented in this paper highlight the importance of considering SWCC

20 hysteresis for a wide range of geotechnical problems, such as soil cover design, prediction of

21 groundwater recharge, contaminant transport through unsaturated soils, soil erosion, slope

22 stability, and swelling/shrinkage of expansive soils. 


\section{$1 \quad$ Keywords}

2 Unsaturated flow; soil-water characteristic curve; hysteresis; climate conditions; numerical

3 modelling; infiltration; surface run-off; moisture movement. 


\section{1. Introduction}

2 Problems involving groundwater flow through unsaturated soils are often analyzed using

3 numerical models. These models require reliable input data for the soil's hydraulic functions for

4 accurate analysis of such problems. The two most commonly used hydraulic functions are: the soil-

5 water characteristic curve (SWCC) and the unsaturated hydraulic conductivity relationship.

6 Hysteresis in the SWCC refers to the non-unique relationship between the soil's matric suction and

7 its water content, whereby the soil can have two different water contents at the same matric

8 suction value, depending on the preceding sequence of wetting and drying. Such hysteresis is

9 thought to be caused by various factors, such as variable and irregular cross-sections of the pores,

10 the different contact angles in the advancing and receding soil-air interface menisci, and the

11 difference in entrapped air volume at different matric suction values. Given that at any given

12 pressure head the soil can have two different water contents - one on the wetting SWCC and the

13 other on the drying SWCC and that the soil's hydraulic conductivity increases with its water

14 content, it is expected that the hydraulic conductivity function will also exhibit hysteresis; however,

15 there is not much evidence of hysteresis in the unsaturated hydraulic conductivity function to be of 16 any practical significance (Stephens 1996).

17 The SWCC is assumed to be non-hysteretic in the numerical analysis of water and solute

18 movement in the unsaturated zone. This assumption is valid when water content is monotonically

19 increasing (e.g. infiltration) or decreasing (e.g. evaporation or gravity drainage); however, under

20 both natural and irrigated environments, the change in soil's water content is affected by time-

21 dependent processes at the surface and is transient and non-monotonic (Russo et al. 1989). That is,

22 at any given time during water redistribution, some portions of the soil may be wetting while

23 others may be drying. Consequently, hysteresis of the SWCC needs to be considered in numerical

24 analysis. The importance of the SWCC hysteresis has been demonstrated in the laboratory and field

25 studies (e.g. Lehmann and Ackerer 1988; Basile et al. 2003); however, hysteresis is usually ignored 
1 using the rationale that the spatial variability of hydraulic properties may overwhelm the local

2 hysteretic effects (Royer and Vachaud 1975). Evidence contrary to this rationale has also been

3 observed (Stauffer and Dracos 1984). Kool and Parker (1987) have pointed out that in many cases

4 neglecting hysteresis is not based on knowledge that its effects are negligible, but rather on

5 expediency motivated by a lack of sufficient data to adequately calibrate the hysteresis model.

While neglecting the SWCC hysteresis may be justifiable under monotonic wetting or

monotonic drying conditions, it becomes very relevant for cyclic wetting and drying processes, such as intermittent precipitation and evaporation. The importance of considering the SWCC hysteresis needs to be assessed for applications such as the design of soil covers, where the design is based on a number of years of climatic data consisting of intermittent precipitation and evaporation events.

11 Soil climate boundary has been cited as the most critical aspect of climate driven processes

12 affecting the stability of geotechnical infrastructure, especially from a climate change perspective

13 (Vardon 2014). Most of the published literature on the effect of the SWCC hysteresis on unsaturated

14 flow is based on controlled infiltration or evaporation events, with virtually no cases involving 15 multi-year climatic data consisting of intermittent precipitation and evaporation records.

This paper presents the results of a numerical modelling exercise to investigate the role of

17 the hysteresis of SWCC on the infiltration characteristics of soils subjected to different climatic

18 conditions within the Canadian province of Alberta. Multi-year climate datasets from four different

19 natural regions and sub-regions of Alberta are compiled and classified. These datasets represent

20 four different climates: wet to moist; neutral; dry; and, very dry. A one-dimensional finite element

21 unsaturated flow model is used to simulate the infiltration and redistribution of water in various

22 soil types. The climate datasets constitute the upper boundary conditions for these simulations.

23 Multiyear simulations are carried out with and without the consideration of hysteresis in the SWCC.

24 Hysteresis in the hydraulic conductivity function was not simulated. The results of the simulations

25 are analyzed in terms of water balance at the ground surface and the temporal distribution and 
1 storage of water within the soil domain. It is demonstrated that the hysteresis of SWCC can

2 significantly affect the prediction of flow, redistribution and storage of water in the unsaturated

3 zone. This finding is also expected to have applications in other geotechnical problems, such as

4 heaving associated with expansive soils, rainfall-induced slope instability, fate and transport of

5 contaminants in the unsaturated zone, and the design of soil covers for waste containment.

\section{2. Climate Data Compilation and Classification}

7 Climate is a critical factor that controls the infiltration characteristics and moisture distribution at

8 any particular site. The ground surface may be subject to extreme weather conditions during a year

9 - from being frozen throughout the winter to thaw and runoff during the spring and vegetation

10 growth and wetting and drying during the summer. The timing, magnitude, and intensity of

11 precipitation events significantly influence runoff generation, infiltration processes and thus the

12 soil moisture regime in the upper portion of the ground.

In order to quantify the effect of climatic conditions on infiltration in soils with hysteretic

14 SWCCs, four different climates from the province of Alberta, Canada were considered. Figure 1

15 shows the summer moisture index (SMI) for the natural regions and sub-regions for the province of

16 Alberta (Natural Regions Committee 2006). SMI is a measure of precipitation effectiveness during

17 the growing season. It is calculated by dividing growing degree-days greater than $5^{\circ} \mathrm{C}$ by the

18 growing season precipitation (April through August). A high SMI value indicates a greater

19 likelihood that at certain times during the growing season there will be less precipitation than the

20 evaporative demand.

21 A SMI values greater than 4 indicates dry to very dry climatic conditions. Grassland Natural

22 Region, Canadian Shield Natural Region, and Peace-Athabasca Delta Natural Sub-region all have SMI

23 values in this range and are likely to have significant moisture deficits for extended periods during

24 the growing season (Natural Regions Committee 2006). SMI values of between 3 and 4 indicate 
1 neither dry nor wet climatic conditions. The likelihood of moderate moisture deficits for short

2 periods during the growing season are expected for the regions with SMI values in this range. All of

3 the Boreal Forest Natural Region except the Boreal Subarctic, Upper Boreal Highlands, and the

4 Central and Peace River Parkland Natural Sub-regions have SMI values of between 3 and 4. An SMI

5 value of less than 3 indicates moist to wet climate conditions, with no moisture deficits during the growing season. Foothills Parkland, Upper Boreal Highlands, and Boreal Subarctic Natural Subregions, and Rocky Mountain and Foothills Natural Regions, all have moist to wet conditions. Four sites representing the moist, neutral, dry and very dry regions in Alberta as described above were selected for climate data compilation and classification. The online interactive tool of Alberta's AgroClimatic Information Service (ACIS) was used to select climate stations within these regions (ACIS 2014). The climate stations were selected based on the availability of daily-resolution continuous records of precipitation, net radiation, maximum and minimum air temperature, maximum relative humidity and wind speeds. It should be noted that these climatic variables not

14 only form the upper boundary of the numerical models but are also required for climate classification of the sites under consideration. not measured at the climate station of interest or there were no continuous records for the years

18 for which other climate variable records were available. As such, global solar radiation data from

19 the nearby locations was used to estimate the net solar radiation at the selected location.

20 Procedures have been developed for predicting net radiation based on equations formulated in

21 terms of total solar radiation, relative humidity, and temperature (Allen et al. 1998; Irmak et al.

22 2003). Total solar radiation, relative humidity, and temperature measurements from the respective

23 climate stations were used to estimate the net radiation. Four climate data sets corresponding to

24 moist, neutral, dry and very dry regions were compiled. Five years of daily climate datasets

25 comprising precipitation, maximum and minimum relative humidity and temperature, wind speed 
1 and net radiation were compiled for neutral, moist and dry regions while the climate dataset for

2 very dry region comprised 4 years of climatic records. Salient characteristics of the four climate

3 data sets are given in Table 1. Daily values of the above mentioned variables were used to estimate

4 the daily potential evaporation (PE) values. The Penman (1948) equation for PE can be written as

5 following (Fredlund et al., 2012):

6

$7 \quad P E=\frac{\Gamma Q_{n}+\eta E_{a}}{\Gamma+\eta}$

9 where $P E$ is the potential evaporation, $Q_{n}$ is the net radiation at the water (or saturated ground)

10 surface, $\eta$ is the psychrometric constant, $\Gamma$ is the slope of saturation vapour pressure versus

11 temperature curve), and $E_{a}$ is as defined as:

12

$13 E_{a}=2.625\left(1+0.146 W_{w}\right)\left(u_{v o}^{a i r}-u_{v}^{a i r}\right)$

15 where $W_{w}$ is the wind speed, $u_{v o}^{\text {air }}$ is the vapor pressure in the air above the water (or saturated

16 ground), surface, and $u_{v}^{\text {air }}$ is the saturated vapor pressure at the mean air temperature.

17 The classification of the climate provides a general weather setting for the site. This is

18 similar to the role that geology plays in understanding the soil conditions at a site. The

19 Thornthwaite climate classification system is an empirical system that was developed from climatic

20 data collected in United States (Thornthwaite 1948; Thornthwaite and Hare 1955). It forms an

21 adequate basis for evaluating the climate for engineering purposes. The 1955 Thornthwaite

22 Moisture Index is computed using Eq. [3] below:

23

$24 \quad I_{m}=100\left(\frac{P}{P E}-1\right)$ 
1 where $I_{m}$ is the 1955 Thornthwaite moisture index, $P$ is the total annual precipitation, and $P E$ is the

2 total annual potential evaporation calculated as the summation of the Penman (1948) monthly

3 potential evaporation values. An $I_{m}$ of zero signifies that the annual precipitation and the potential

4 evaporation are equal. While $P E$ is used for climate classification, it is the Actual Evaporation $(A E)$

5 and Actual Transpiration (AT) that are of greatest importance when assessing the actual loss of

6 moisture from a soil surface. Figure 2 shows the $I_{m}$ values for the four sites. It can be seen in Figure

72 that the compiled datasets cover a range of conditions from Semi-Arid to Moist Humid. It should

8 also be noted that the data presented in Figure 2 also capture the year-to-year variations in

9 climates for the four selected sites.

\section{3. Methodology}

\section{$11 \quad 3.1$ Theoretical Background}

12 Water flow in unsaturated porous medial can be represented by Richards's equation (Richards

13 1928; 1931). For one-dimensional vertical flow, the mixed form of Richards's equation can be

14 written as:

$16 \quad \frac{\partial \theta}{\partial t}=\frac{\partial}{\partial z}\left[K(\theta)\left(\frac{\partial \psi}{\partial z}-1\right)\right] \pm S$

18 where $\theta$ is the volumetric water content, $t$ is time, $z$ is the spatial coordinate, $K(\theta)$ is the unsaturated

19 hydraulic conductivity function, $\psi$ is the suction or pressure head and $S$ is a general sink or source

20 term. An important aspect of the Richards's equation is that the water content and the unsaturated

21 hydraulic conductivity are highly nonlinear functions of suction. The relationship between water

22 content and suction is given by the SWCC. The relationship between unsaturated hydraulic

23 conductivity and suction (or water content) is given by the unsaturated hydraulic conductivity 
1 function, which is also commonly referred to as the $K$-function. One of the most commonly used

2 closed-form empirical equation for the SWCC is the one proposed by van Genuchten (1980):

3

$4 \quad S_{e}=\frac{\theta(\psi)-\theta_{r}}{\theta_{s}-\theta_{r}}=\left[1+|\alpha \psi|^{n}\right]^{-m}$

5

For the $K$-function, the following equation proposed by Mualem (1976) is frequently used:

$8 \quad K(\psi)=K_{s}\left(S_{e}\right)^{l}\left[1-\left\{1-\left(S_{e}\right)^{1 / m}\right\}^{m}\right]^{2}$

In Eqs. [5] and [6], $K_{s}$ is the saturated hydraulic conductivity, $S_{e}$ is the effective water

11 saturation $\left(0<\mathrm{S}_{\mathrm{e}}<1\right), \theta_{s}$ is the saturated volumetric water content, $\theta_{r}$ is the residual volumetric

12 water content, and $\alpha, n$ and $m$ are empirical parameters that depend on the soil type and can be

13 estimated by fitting Eq. [5] to the measured SWCC data. The parameter $m$ is commonly assumed to

14 be equal to $1-1 / n$ (van Genuchten 1980). In Eq. [6], $l$ is the pore interaction factor and its value has

15 been found to be 0.5 for a wide variety of soils (Mualem 1976).

16 A number of models for hysteresis in the SWCC and the $K$-function have been proposed over

17 the past several decades. Comprehensive reviews of these hysteresis models have been provided by

18 Viaene et al. (1994), Pham et al. (2005), and Bashir (2007). One of the most widely used hysteresis

19 models for the SWCC and the $K$-function was proposed by Kool and Parker (1987). They combined

20 the van Genuchten (1980) $K-\theta-\psi$ model with the empirical hysteresis model of Scott et al. (1983)

21 to derive a new model of capillary hysteresis, which is capable of taking into account the effect of

22 air entrapment. The model provides closed-form expressions for hysteretic SWCC and $K$-function.

23 The Kool and Parker (1987) hysteresis model predicts the drying and wetting scanning

24 curves by scaling the main curves. The main hysteresis loop, which is composed of the main drying

25 curve (MDC) and the main wetting curve (MWC), is defined by Eq. [5]. This leads to a parameter 
1 vector $\left\{\theta_{s}^{d}, \theta_{r}^{d}, \alpha^{d}, n^{d}\right\}$ for the MDC and $\left\{\theta_{s}^{w}, \theta_{r}^{w}, \alpha^{w}, n^{w}\right\}$ for the MWC, resulting in 8 unknown

2 parameters. The simplest formulation for the Kool and Parker (1987) model assumes $\theta_{s}^{w}=\theta_{s}^{d}=\theta_{s}$

3 and $\theta_{r}^{w}=\theta_{r}^{d}=\theta_{r}$, thereby ensuring that the main hysteresis loop is closed and the total number of

4 unknown parameters is reduced to 6. Once the parameters for the main hysteresis loop are known,

5 the drying and wetting scanning curves can be scaled from the MDC and the MWC, respectively.

6 Drying scanning curves can be predicted by scaling the MDC to pass through the residual

7 volumetric water content $\theta_{r}$ and the last reversal point from wetting to $\operatorname{drying}\left({ }^{\Delta} \theta,{ }^{\Delta} \psi\right)$ by replacing

8 the saturated volumetric water content $\theta_{s}^{d}$ in the parameter vector $\left\{\theta_{s}^{d}, \theta_{r}^{d}, \alpha^{d}, n^{d}\right\}$ by:

$10 \quad \theta_{s}^{*}=\frac{\Delta_{\theta}\left(\theta_{s}-\theta_{r}\right)-\theta_{r}\left[\theta_{s}-\theta^{d}\left({ }^{\Delta} \psi\right)\right]}{\theta^{d}\left(\Delta^{\Delta} \psi\right)-\theta_{r}}$

12 Similarly, wetting scanning curves can be predicted by scaling the MWC to pass through the

13 saturated volumetric water content $\theta_{s}$ and the last reversal point from drying to wetting $\left({ }^{\Delta} \theta,{ }^{\Delta} \psi\right)$ by 14 replacing the residual volumetric water content $\theta_{r}^{w}$ in the parameter vector $\left\{\theta_{s}^{w}, \theta_{r}^{w}, \alpha^{w}, n^{w}\right\}$ by:

$16 \quad \theta_{r}^{*}=\frac{\Delta_{\theta}\left(\theta_{s}-\theta_{r}\right)-\theta_{s}\left[\theta^{w}(\Delta \psi)-\theta_{r}\right]}{\theta_{s}-\theta^{w}(\Delta \psi)}$

By setting $n^{w}=n^{d}=n$, a non-hysteretic $K$-function is obtained from the Kool and Parker (1987) model and the size of the parameter vector gets reduced by 1; however, doing so results in a loss of flexibility in terms of specifying the MDC and the MWC as $\alpha$ is the only parameter left that can be

21 used to define the differences between the MDC and the MWC.

23 scanning hysteresis loops that are closed. For example, in a scanning hysteresis loop consisting of

24 the primary wetting and secondary drainage scanning curves, the secondary drainage curve does 
1 not pass through the point where the wetting scanning curve departs the main drying curve. As a

2 result, a pumping effect occurs when the system undergoes the cyclic variations in pressure head.

3 Such cyclic variations exist in systems such as transport above a tidally-forced water table and

4 infiltration and redistribution under periodic irrigation as pointed out by Werner and Lockington

5 (2006).

The model of Parker and Lenhard (1987) uses a scaling procedure similar to that used by

7 Scott et al. (1983) and Kool and Parker (1987); however, in this model, the scaling procedure

8 enforces the closure of scanning loops by scaling the scanning curves to pass back through the

9 reversal points. Similar to the Kool and Parker (1987) model, the MDC and the MWC for the Parker

10 and Lenhard (1987) model are described by the van Genuchten (1980) equation (Eq. [5]). The

11 wetting scanning curves are predicted using the following equation:

$13 S(\psi)=\frac{\left[S_{e}^{w}(\psi)-S_{e}^{w}\left({ }^{\Delta} \psi^{w d}\right)\right]\left({ }^{\Delta} S_{e}^{d w}-{ }^{\Delta} S_{e}^{w d}\right)}{S_{e}^{w}\left({ }^{\Delta} \psi^{d w}\right)-S_{e}^{w}\left({ }^{\Delta} \psi^{w d}\right)}+{ }^{\Delta} S_{e}^{w d}$

15 where $S_{e}^{w}$ is the effective saturation calculated using the van Genuchten (1980) equation (Eq. [5])

16 with parameter vector $\left\{\theta_{s}^{w}, \theta_{r}^{w}, \alpha^{w}, n^{w}\right\}$. The superscript $\Delta$ indicates a reversal point value, and

17 superscripts $w d$ and $d w$ indicate reversal from wetting to drying and drying to wetting,

18 respectively. Similarly, drying scanning curves are predicted using:

$20 S(\psi)=\frac{\left[S_{e}^{d}(\psi)-S_{e}^{d}\left(\Delta^{\Delta} \psi^{w d}\right)\right]\left({ }^{\Delta} S_{e}^{w d}-{ }^{\Delta} S_{e}^{d w}\right)}{S_{e}^{w}\left({ }^{\Delta} \psi^{w d}\right)-S_{e}^{w}\left({ }^{\Delta} \psi^{d w}\right)}+{ }^{\Delta} S_{e}^{d w}$

22 where $S_{e}^{d}$ is the effective saturation calculated using the van Genuchten (1980) equation (Eq. [5])

23 with parameter vector $\left\{\theta_{s}^{d}, \theta_{r}^{d}, \alpha^{d}, n^{d}\right\}$. The Parker and Lenhard (1987) model eliminates the 
1 pumping effect but at the cost of increased memory storage requirements because it requires the

2 storing of previous reversal points so as to be able to pass the scanning curves through them.

3

\section{$4 \quad 3.2$ Development of the Numerical Model}

5 A one-dimensional numerical model of the soil profile was developed using the Hydrus-1D software

6 (Šimůnek et al. 2013) to simulate the effects of hysteresis of SWCC and climatic conditions. Hydrus-

$7 \quad 1 \mathrm{D}$ is a finite element program for simulating the transport of water, heat and multiple solutes in a

8 variably saturated porous media. It is capable of handling hysteretic soil hydraulic functions and

9 soil-atmosphere boundary conditions. The profile depth of the numerical model was set at $1 \mathrm{~m}$.

10 Initially, the finite element models were developed by dividing the entire vertical profile into 1001 -

11 cm-thick layers. Nodal spacing was adjusted in various models to achieve convergence.

A zero-gradient boundary condition was used at the bottom of the soil profile to simulate a

13 freely draining soil profile. This boundary condition is most appropriate for situations where the

14 water table lies far below the domain of interest (Šimůnek et al. 2013). One of the four different

15 climatic datasets was applied as the top boundary condition of the soil profile. This boundary

16 condition was implemented by providing Hydrus-1D with a daily time history of precipitation $(P)$

17 and potential evaporation $(P E)$ values. The $P E$ values were calculated using the daily temperature,

18 relative humidity, wind speed and net radiation data employing Penman (1948) method. It should

19 be noted that climate data at the most sites was only available at a daily resolution.

The boundary representing the soil-air interface, which is also known as the soil-

21 atmosphere boundary, is a special type of boundary where the flux, pressure or the gradient is not

22 known a priori. The potential flux across this boundary is dependent on the soil atmospheric

23 conditions, namely: precipitation; minimum and maximum relative humidity and temperature;

24 wind speed; and, net radiation. The actual surface flux at this boundary also depends on the

25 transient moisture condition in the soil near the ground surface. In instances where the moisture 
1 availability in the soil at the surface is limited, the evaporation rate at the surface is reduced to a

2 value commonly known as actual evaporation $(A E)$. In instances when the head at the ground

3 surface is greater than a critical minimum head value $\left(\psi_{A}\right)$, a flux equal to potential evaporation rate

4 is prescribed. For situations where the head at the soil surface falls below this critical value, actual

5 evaporation rate at the soil surface is calculated by estimating the flux at the potential head at the

6 soil surface (Vanderborght et al. 2010). Another important aspect of the soil-atmosphere boundary

7 is that it can change from a prescribed flux to a prescribed head and vice versa. The other instance

8 where the switch from prescribed flux to head and vice versa may happen is when the precipitation

9 rate exceeds the infiltration capacity of the soil. Precipitation in excess of the infiltration capacity

10 will either result in generation of instantaneous runoff or accumulation of water on the soil surface

11 (ponding). Runoff generation or build-up of head at the soil surface depends on the maximum

12 allowed pressure head at the soil surface $\left(\psi_{s}\right)$ and is related to the soil surface condition.

13 The soil-atmosphere boundary in Hydrus-1D is implemented by means of a system dependent

14 boundary condition using the approach proposed by Neuman et al. (1974). The boundary condition

15 limits the absolute value of the flux such that the following two conditions are satisfied:

$17\left|-K(\psi)\left(\frac{\partial \psi}{\partial x}+1\right)\right| \leq E$

18 and,

$19 \psi_{A} \leq \psi_{s}$

21 where $E$ is the maximum potential rate of infiltration or evaporation under the current atmospheric

22 conditions, $\psi$ is the pressure head at the soil surface, and $\psi_{A}$ and $\psi_{S}$ are, respectively, the minimum

23 and the maximum pressure heads allowed under the prevailing soil conditions. The minimum

24 pressure head at the soil surface allowed under the prevailing soil conditions, $\psi_{A}$, can be calculated

25 from the air humidity, $H_{r}$, as follows (Šimůnek et al. 2013): 
$1 \quad \psi_{A}=\frac{R T}{M g} \ln \left(H_{r}\right)$

2

3 where $M$ is the molecular weight of water, $g$ is the gravitational acceleration, and $R$ is the gas

4 constant, $T$ is the temperature and the other varaibles are as described above. Details of the the

5 methods for calculating $E$ and $\psi_{A}$ on the basis of atmospheric data have been discussed by Feddes

6 et al. (1974).

Although the weather condition at the ground surface can be highly variable throughout the

8 year, the infiltration numerical modelling can be simplified considerably by realizing that the soil-

9 atmospheric analyses are most responsive during the period when the ground surface is thawed. As

10 such, each year of the simulation can be divided into active and inactive time periods

11 (Fredlund et al. 2013). The active period represents thawed ground conditions when precipitation

12 can either make its way into the ground as infiltration, or can flow away as runoff. The inactive

13 period represents the period when the ground is frozen and precipitation accumulates on the

14 ground surface as snow. For each of the four sites the first date of freezing (i.e., the start of winter)

15 was selected based on the review of multi-year air temperature records from the climatic data for

16 that site. Spring-like conditions consists of a period where the precipitation that has accumulated

17 over the winter is applied as a major infiltration event. The first date of spring (i.e., a date on which

18 the soil is expected to be thawed) was also selected based on the review of multi-year air

19 temperature records from the climatic dataset for that particular site. The number of days from the

20 start of the spring to the start of the freezing period was identified as the active period and the

21 simulations were run for this active period. The precipitation from the date of the previous year's

22 freeze-up to the date of the current year's spring thaw was assumed to be snow. It was assumed

23 that $50 \%$ of the snow was lost through sublimation and spring runoff. The other half of the snow

24 was applied as a spring infiltration event in the first two weeks of spring. 


\subsection{Simulation Details}

2 Simulations were designed to investigate the effects of climate type, degree of hysteresis in SWCC,

3 and precipitation intensity on the infiltration behaviour. The effect of climate type was quantified

4 by carrying out twelve different simulations. A set of three simulations were carried out, for each of

5 the four different climate types, namely: wet, neutral, dry and very dry. For each of the climate type

6 three simulations were run with soil hydraulic properties corresponding to drying, wetting and

7 hysteretic parameters. For these simulations a loamy soil was selected from the UNSODA database

8 (soil U4910 from Gebrenegus and Ghezzehei 2011 or Nemes et al. 1999) and was labelled Soil 1.

9 The van Genuchten (1980) parameters for Soil 1 are provided in Table 2. The hysteretic SWCC

10 curves for Soil 1 are shown in Figure 3. Hysteresis was simulated using the model of Parker and

11 Lenhard (1987). An inspection of the wetting and drying SWCCs for Soil 1 indicates that hysteresis

12 could be significant for this soil if flow reversals were to occur, given the relatively large separation

13 between the main draining and wetting branches of the curves. For all the models, the initial

14 volumetric water content was specified to be $0.4 \mathrm{~cm}^{3} / \mathrm{cm}^{3}$ constant with depth, in order to ensure

15 that the hysteretic and non-hysteretic models have similar initial storages. Setting the initial

16 condition in suction would have resulted in different storages owing to the different water holding

17 capacities at similar suction values. This would have complicated the comparing of change in

18 storage for different models.

19 Twenty-four additional simulations were conducted to assess the effect of degree of

20 hysteresis on the infiltration behaviour. In addition to Soil 1 used for the set of simulations

21 conducted to investigate the effect of climate type, two other soils labelled Soil 2 and Soil 3 were

22 used. Soil 2 was a silty sand reported by Yang et al. (2004). Soil 3 was soil K0004 reported by

23 Gebrenegus and Ghezzehei (2011) and had the texture of silty loam. The drying and wetting SWCCs

24 for Soil 2 and Soil 3 are shown in Figure 3. The van Genuchten (1980) parameters for Soil 2 and Soil

253 are given in Table 2. In terms of the degree of hysteresis in their respective SWCCs as defined by 
$1\left\{\max \left(\theta^{d}-\theta^{w}\right)\right\}$ in Figure 3, Soil 1 had the highest and Soil 2 had the lowest degree of hysteresis.

2 Twelve simulations were carried out using hydraulic properties of Soil 2 and other twelve

3 simulations were conducted using hydraulic properties of Soil 3. Drying, wetting and hysteretic

4 simulations were conducted for each soil type. Each set of drying, wetting or hysteretic simulations

5 for each soil type used the four different climatic conditions. The other details of these simulations

6 were the same as those described above for the initial set of simulations conducted to investigate

7 the effect of climate type. The initial conditions of these models were set at $50 \%$ saturation

8 volumetric water content.

9 The climate records used in the present study were only available at a daily resolution,

10 which means the precipitation $(P)$ and the potential evaporation $(P E)$ were applied as distributed

11 over a 24-hour period. In reality, precipitation events can and do occur over a time interval much

12 shorter than 24 hours. Such intense precipitation events may overwhelm the infiltration capacity of

13 a soil and result in generation of surface run-off. It is hypothesized that these shorter-duration

14 precipitation events may also result in more significant moisture content reversals, resulting in

15 more pronounced hysteretic behaviour. Three additional simulations were carried out using Soil 2

16 to test this hypothesis. For these three simulations, dry climate type was used but the intensity of

17 the precipitation event was increased by applying the total daily precipitation over a 6-hour period

18 while applying the daily $P E$ values over the 24-hour period. The saturated hydraulic conductivity of

19 Soil 2 was reduced by a factor of 10 to further increase the possibility of run-off generation. These

20 simulations were run using both hysteretic and non-hysteretic SWCCs.

\section{4. Results and Discussion}

22 The results of the simulations are presented in many different ways such as: water balance at the

23 ground surface, overall water balance of the complete soil domain, and temporal information on

24 moisture distribution with depth. The results are presented in this manner to highlight the 
1 importance of these simulations results to actual engineering applications. The water balance at the

2 ground surface is of interest to those involved with soil cover design or predicting ground water

3 recharge as it provides information on the quantity of the meteoritic water that moves past the

4 ground surface overcoming evaporation and runoff. Similarly temporal information on moisture

5 distribution with depth is important for studies regarding contaminant transport or shrinkage and

6 swelling behaviour of expansive soils.

\subsection{Effect of Climate Type}

9 In this section, the results from the set of simulations conducted to investigate the effect of climate

10 type on infiltration behavior with and without hysteretic SWCC are presented and discussed. For

11 the sake of brevity, the results for the hysteretic and non-hysteretic simulations corresponding to

12 one climate type (dry climate) are presented first and explained in detail. The comparisons

13 between hysteretic and non-hysteretic simulations for all climate types are then presented to

14 provide the reader an insight on the importance of hysteresis for various climate types. The

15 simulations run with hysteretic, drying and wetting SWCCs are referred to as HC, DC and WC

16 simulations, respectively.

17 Water balance for the hysteretic and non-hysteretic simulation with dry climatic conditions

18 is shown in Figure 4 in which the net infiltration $(N I)$ is the quantity of meteoric water that

19 overcomes the evaporation and makes its way into the soil profile. It is calculated as follows:

$21 \quad N I=P-A E-R O$

23 where $R O$ is the surface runoff and the other quantities have been defined previously. Similarly, the

24 bottom flux in Figure 4 refers to the quantity of water that flows through the soil profile and drains

25 through the bottom boundary of the soil domain. With the exception of $R O$, all quantities were 
1 considered positive into the soil domain and negative out of the soil domain. $R O$ is always

2 considered positive. It should be noted that daily values of P and PE are plotted in Figure 4 instead

3 of plotting their cumulative values in order to achieve a reasonable resolution for the cumulative

$4 \quad A E, R O, N I$ and bottom flux plots.

5 A number of important observations can be made from Figure 4. Firstly, the cumulative $A E$

6 for all the simulations is around $1400 \mathrm{~mm}$, which is nearly half of the cumulative $P E$ of $2709 \mathrm{~mm}$.

7 This is because of the soil-atmosphere boundary, which reduces the evaporation from the potential

8 value depending on the prevailing water conditions in the soil layer at the ground surface. Secondly,

9 the $A E$ values for the HC and DC simulations are similar and substantially higher than the WC

10 simulation. The lower $A E$ value for the WC simulation implies that less water was retained in the

11 soil layer near ground surface for the WC simulation compared with the HC and DC simulations,

12 resulting in reduced evaporation. Such result is expected because for the same soil the water-entry

13 value (WEV) for the MWC is lower than that for the air entry value (AEV) of MDC. As such, for the

14 WC simulation, smaller amount of water was retained by the soil near the ground surface compared

15 with the HC and DC simulations, which, in turn, reduced the quantity of water available for

16 evaporation. This observation is also consistent with the general understanding that coarse-grained

17 soils are good evaporation barriers owing to their lower water retention characteristics.

18 The WC simulation had the largest cumulative NI whereas the HC simulation had the lowest

19 cumulative NI (Figure 4). The WC simulation showed largest cumulative NI because of the lowest

20 cumulative $A E$ as per Eq. [14]. The HC simulation showed lowest cumulative $N I$ because it had the

21 highest cumulative $A E$ and nearly as much cumulative $R O$ as the WC simulation (close to $100 \mathrm{~mm}$ ).

22 The DC simulation predicted the lowest cumulative $R O$ (around $30 \mathrm{~mm}$ ) among the three

23 simulations. The differences in cumulative $R O$ values for the three simulations can be explained

24 with the help of Figure 5, which shows temporal distributions of volumetric water content $\theta$,

25 cumulative $R O$ and $(P-P E)$ for the three simulations. The numerical model predicts surface runoff 
1 when the soil near the ground surface gets saturated (i.e., $\theta=\theta_{S}$ ) and the potential surface flux

2 intensity is greater than the saturated hydraulic conductivity of the soil (i.e. $(P-P E)>$ Ksat). As

3 seen in Figure 5, this condition is achieved more frequently for the HC and WC simulations than for

4 the DC simulation because in the $\mathrm{HC}$ and the WC simulations the soil follows either the MWC or the

5 scanning wetting curve whereas the soil follows the MDC in the DC simulations. Soil that is

6 following a wetting curve will get saturated more quickly and more frequently than the soil that

7 follows a drying curve, thereby triggering surface runoff conditions more frequently.

The WC simulation predicts the largest value of cumulative bottom flux $(B F)$ among the

9 three simulations (Figure 4), which is expected since the WC simulation had the greatest quantity of

10 water entering the system (highest cumulative $N$ I). Since the soil was following the MWC in the WC

11 simulation, it had lower WEV and hence lower water retention capacity compared with the soil in

12 the HC and DC simulations. The observation that the HC and DC simulations predicted lower

13 cumulative $B F$ is significant from the viewpoint of soil cover design in which the control of water

14 infiltration is the primary objective.

15 The temporal changes in the storage in Soil 1 for the three simulations are shown in

16 Figure 6. The storage for the WC simulation is the highest throughout the time period, which is

17 consistent with its having the highest cumulative NI. The storage for the HC simulation is either

18 similar to or slightly lower than that for the DC simulation for most of the time period except

19 towards the end of the time period, where the storage for the HC simulation exceeds that of the DC

20 simulation. It is interesting to note that storage values for the three simulation are very similar at

21 the start and end of the simulation. However, it should also be noted that values vary within the

22 course of the simulations. As pointed out previously, a lot more water passes through the system in

23 the WC simulation compared with the HC or DC simulations. These differences in the change of

24 storage for the three simulations are important for the systems involving downward migration of

25 contaminants or for groundwater recharge estimates. 
Figure 7 shows the driest and the wettest water content profiles with depth for the first

2 year of the total simulated time period for the DC, HC and WC simulations. For driest profile, which

3 is related to a drying event the $\mathrm{HC}$ simulation resembles the $\mathrm{DC}$ simulation whereas for wettest

4 profile, which is related to a wetting event, the HC simulation resembles the WC simulation.

5 Consequently, the HC simulation predicts the largest variation in water content with depth during a calendar year. Difference in moisture content variations would predict different estimates of movements in expansive soils due to swelling and shrinkage. In such instances, ignoring the effect

8 of hysteresis of the SWCC could potentially lead to inaccurate estimates of such movements.

A comparison of the cumulative values of $A E, N I, R O$ and $B F$ for the DC, WC and HC

10 simulations with different climatic condition is presented in Figure 8. It is evident from Figure 8

11 that observations similar to those made previously for the dry climate can be made for the wet,

12 neutral and very dry climates. For all four climate types the cumulative $A E$ is always the greatest for

13 the HC simulation and the cumulative $N I$ always the greatest for the WC simulation. The HC and the

14 WC simulations predict nearly the same values for cumulative $R O$ regardless of the climate type.

15 The cumulative values of $N I, R O$ and $B F$ increase as the climatic conditions become wetter; this is

16 because of higher cumulative $P$ and higher TMI for wetter climatic conditions. Overall, the

17 predictions from the HC simulations are significantly different from the DC and WC simulations.

18 This observation emphasizes the importance of considering hysteresis irrespective of the climate

19 type.

\section{$21 \quad 4.2$ Effect of Degree of Hysteresis in SWCC}

22 Figure 9 shows the cumulative values of $A E$ and $N I$ for the three soil types obtained from the DC, WC 23 and HC simulations for the four different climate types. It is worth recalling that Soil 1 had the

24 highest and Soil 2 had the lowest degree of hysteresis as defined by $\left\{\max \left(\theta^{d}-\theta^{w}\right)\right\}$ (Figure 3). 
1 The cumulative $A E$ and $N I$ values for Soil 2 for the hysteretic and non-hysteretic simulations are

2 very similar. This is an expected result since Soil 2 had the lowest degree of hysteresis in its SWCC.

3 The greatest difference in cumulative $A E$ and $N I$ values between the hysteretic and non-hysteretic

4 simulations was exhibited by Soil 1, which had the highest degree of hysteresis in its SWCC. For

5 both Soil 2 and Soil 3, however, the cumulative $A E$ and $N I$ values obtained from the HC (hysteretic)

6 simulation are very close to those obtained from the DC (drying) simulation.

It has been reported in the literature that, owing to the small time steps required for convergence of numerical solution, sometimes the hysteresis algorithm in Hydrus-1D may not be

9 able to capture the moisture content reversals (Bashir et al. 2009). It was prudent, therefore, to

10 confirm that the prediction of very similar cumulative $A E$ and $N I$ values by the HC and DC

11 simulations was not because of problems with the hysteresis algorithm in Hydrus 1-D. Satisfactory

12 performance of the hysteresis algorithm can be established by superimposing the paired water

13 content-suction data points at a given node on the hysteretic SWCC for the soil.

Figure 10 shows the paired water content-suction data from the top node for the HC, DC

15 and WC simulations for Soil 2, superimposed on the hysteretic SWCC for this soil. As seen in Figure

1610 , the paired data points from the DC simulation plot on the MDC and those from the WC

17 simulation plot on the MWC. The paired data points from the HC simulation plot on the MDC, MWC

18 or scanning curves depending on the drying and wetting history of the soil. It can also be observed

19 from Figure 10 that Hydrus-1D generates scanning curves as the soil goes through the drying and

20 wetting cycles in response to the infiltration and evaporation/drainage events.

21 As an additional check on the hysteresis algorithm, the switching of hysteresis at various

22 spatial locations was compared with the reversal of water content. Hydrus-1D assigns a hysteresis

23 index $\kappa$ to each node (Šimůnek et al. 2013). Wetting is indicated by setting $\kappa=1$ and drying is

24 indicated by setting $\kappa=-1$. Figure 11 compares the hysteresis index to the moisture content time

25 history at three different spatial locations for a part of the HC (hysteretic) simulation for Soil 2. It 
1 can be seen in Figure 11(a) that the upper layer of the soil is exposed to atmospheric conditions and

2 therefore undergoes numerous reversals. This gradually decreases with depth as can be seen in

3 Figure 11(b) for $0.5 \mathrm{~m}$ depth and in Figure 11(c) for $1 \mathrm{~m}$ depth.

$4 \quad$ It is evident from the results presented in Figures 10 and 11 that the hysteresis algorithm in

5 Hydrus-1D was working satisfactorily and was able to capture the moisture content reversals accurately. These results confirm the importance of hysteretic SWCC for accurate simulation of the

7 effect of hysteresis and highlight the importance of the accurate measurement of the both the

8 drying and the wetting branches of the hysteretic SWCC.

\subsection{Effect of Precipitation Intensity}

11 The results presented in the previous section indicated that relatively small differences between

12 the hysteretic and non-hysteretic simulations for Soils 2 and 3 were in part because of their lower

13 degrees of SWCC hysteresis. However, part of the difference between the hysteretic and non-

14 hysteretic simulations for Soil 1 can also be attributed to runoff generation. For Soil 1, the WC and

15 HC simulations generated significantly more cumulative $R O$ than that generated by the DC

16 simulation (Figure 5). The saturated hydraulic conductivity values for Soil 2 and Soil 3 are,

17 respectively, one and two orders of magnitude higher than that for Soil 1 . Their higher hydraulic

18 conductivity and the fact that the climatic conditions could only be obtained and applied at daily

19 resolution resulted in no runoff generation for Soil 2 and Soil 3. In reality the precipitation events

20 almost always occur over a shorter time interval than 24 hours and may overwhelm the infiltration

21 capacity of the soil, resulting in runoff generation. Shorter duration of precipitation may also

22 induce greater number of moisture content reversals, resulting in more pronounced hysteretic

23 behaviour. In this section, the above hypothesis is tested using the results of three additional

24 simulations using Soil 2 in which the precipitation intensity was increased by applying the total

25 daily precipitation in 6 hours, but keeping the potential evaporation distributed over the 24-hour 
1 period. Further details of these simulations have been provided previously in the Simulation Details

2 section.

3 The water balance the ground surface and water flux from the bottom of the domain for

4 these simulations are presented in Figure 12. It is evident from Figure 12 that the hysteretic and

5 non-hysteretic simulations show distinctly different values of cumulative $A E, N I$ and $B F$ for a more

6 intense (shorter duration) precipitation event. This observation also emphasizes the importance of

7 collecting and using climatic data at appropriate resolution in order to simulate the hysteretic

8 behaviour accurately.

\section{5. Conclusions}

10 This paper presented the results of a numerical modelling exercise to investigate the role of the

11 hysteresis of SWCC on the infiltration characteristics of soils subjected to different climatic

12 conditions within the Canadian province of Alberta. Multi-year climate datasets from four different

13 natural regions and sub-regions of Alberta were compiled and classified. These datasets represent

14 four different climates: wet to moist; neutral; dry; and, very dry. A one-dimensional finite element

15 unsaturated flow model was used to simulate the infiltration and redistribution of water in various

16 soil types. The climate datasets constituted the upper boundary conditions for these simulations.

17 Multiyear simulations were carried out with and without the consideration of hysteresis in the

18 SWCC. The results of the simulations were analyzed in terms of water balance at the ground surface

19 and the temporal distribution and storage of water within the soil domain. The following

20 conclusions can be drawn from the results presented in this paper:

21 1. The consideration of hysteresis in the SWCC of a soil will result in the prediction of significantly

22 different infiltration characteristics than those predicted using a non-hysteretic SWCC.

23 2. It is important to consider hysteresis of SWCC for all climate types ranging from very dry to wet. 
13 . The greater the degree of hysteresis in a soil's SWCC, the more pronounced the differences

2 between the predictions from hysteretic and non-hysteretic simulations.

3 4. In case of soils that exhibit hysteresis of SWCC, consideration of hysteresis results in prediction

$4 \quad$ of lower infiltration and less movement of water through the soil.

5 5. Regardless of the climatic conditions and the type of soil, the use of wetting hydraulic parameters results in prediction of increased infiltration and movement of water compared with the predictions using the drying or hysteretic hydraulic parameters.

6. For soils that exhibit greater degree of hysteresis, it is important to measure both the drying and the wetting branches of the SWCC accurately.

7. Accurate simulation of hysteretic behaviour requires climate data records at appropriate 11 resolution.

12 The results presented in this paper highlight some very important considerations of 13 practical relevance and applications. The consideration of hysteresis will result in predictions of

14 lower infiltration of meteoric water and greater runoff generation, which will have implications for 15 soil cover design, prediction of groundwater recharge and fate and transport of contaminants in the 16 unsaturated zone. Similarly, prediction of greater runoff generation will be of interest to

17 practitioners involved in studying the erosion behaviour of soils. Differences in water distribution

18 with depth, its temporal physiognomies and severity between hysteretic and non-hysteretic

19 simulations will affect the prediction of swelling/shrinkage behaviour of expansive soils. The

20 differences in quantity and distribution of water will also have implications for slopes where

21 suction plays an important part in stability assessment. 


\section{Acknowledgements}

The authors acknowledge the Natural Sciences and Engineering Research Council (NSERC) of Canada and Lassonde School of Engineering, York University for partially funding the research presented in this paper.

\section{References}

ACIS 2014. AgroClimatic Information Service (ACIS) Portal. Alberta Ministry of Agriculture and Rural Development. Available on-line at http://agriculture.alberta.ca/acis/ (accessed 31 Dec, 2014).

Allen, R. G., Pereira, L. S., Raes, D., and Smith, M. 1998. Crop Evapotranspiration: Guidelines for Computing Crop Water Requirements. FAO - Food and Agriculture Organization of the United Nations, Rome, Italy, $24-47$.

Bashir, R. 2007. Quantification of surfactant induced unsaturated flow in the vadose zone. Ph.D. dissertation, McMaster Univ., Hamilton, ON, Canada.

Bashir, R., Smith, J., Stolle, D., and Henry, E. 2009. On the importance of hysteresis in numerical modelling of surfactant-induced unsaturated flow. Soil Sediment Contamination: An International Journal, 18(3): 264-283.

Basile, A., Ciollaro, G., and Coppola, A. 2003. Hysteresis in soil water characteristics as a key to interpreting comparisons of laboratory and field measured hydraulic properties, Water Resources Research, 39(12): 1355, doi:10.1029/2003WR002432, 12.

Feddes, R. A., Bresler, E., and Neuman, S.P. 1974. Field test of a modified numerical model for water uptake by root systems, Water Resources Research, 10(6): 1199-1206.

Fredlund, D.G., Rahardjo, H. and Fredlund, M.D. 2013. Unsaturated Soil Mechanics in Engineering Practice, Wiley, Hoboken, NJ, USA. 
Gebrenegus, T., and Ghezzehei, T.A. 2011. An index for degree of hysteresis in water retention, Soil Sci. Soc. Am. J., 75(6): 2122-2127.

Irmak, S., Irmak, A., Jones, J. W., Howell, T. A., Jacobs, J. M., Allen, R. G., and Hoogenboom, G. 2003. Predicting Daily Net Radiation Using Minimum Climatological Data. Journal of Irrigation and Drainage Engineering, 129(4): 256 - 269.

Kool, J. B. and Parker, J. C. 1987. Development and evaluation of closed-form expressions for hysteretic soil hydraulic properties. Water Resources Research, 23(1):105 - 114.

Lehmann, F. and Ackerer, P. 1998. Comparison of iterative methods for improved solutions of the fluid flow equation in partially saturated porous media. Transport in Porous Media, 31(3): 275 $-292$.

Mualem, Y. 1976. A new model for predicting the hydraulic conductivity of unsaturated porous media. Water Resources Research, 12(3): 513-522.

Natural Regions Committee. 2006. Natural Regions and Sub-regions of Alberta. Compiled by D.J. Downing and W.W. Pettapiece. Government of Alberta Pub. No. T/852. Edmonton, Alberta. Available on-line at http://www.cd.gov.ab.ca/preserving/parks/anhic/Natural region report.asp (accessed 31 Dec 2014).

Nemes, A., Schaap, M.G. and Leij, F.J. 1999. UNSODA database of unsaturated soil hydraulic properties. v. 2.0 ed. USDA Agric. Res. Serv., Washington, DC.

Neuman, S. P., Feddes, R. A., and Bresler, E. 1974. Finite element simulation of flow in saturatedunsaturated soils considering water uptake by plants. Third Annual Report, Project No. A10SWC-77, Hydraulic Engineering Lab., Technion, Haifa, Israel.

Parker, J. C. and Lenhard, R. J. 1987. A model for hysteretic constitutive relations governing multiphase flow: 1. Saturation-pressure relations. Water Resources Research, 23(12): 21872196. 
Penman, H.L. 1948. Natural evaporation from open water, bare soil and grass. Proc. Roy. Soc. London A(194): 120-145.

Pham, H.Q., Fredlund, D. G., and Barbour, S. L. 2005. A study of hysteresis models for soil-water characteristic curves. Canadian Geotechnical Journal, 42(6):1548 - 1568

Richards, L. A. 1928. The usefulness of capillary potential to soil moisture and plant investigators. J. Agric. Res., 37(12): 719-742.

Richards, L. A. 1931. Capillary conduction of liquids through porous mediums. Physics (N.Y.), 1(5): 318-333.

Royer, J.M. and Vachaud, G. 1975. Field determination of hysteresis in soil-water characteristics. Soil Sci. Soc. Am. J.: 39(2): 221-223.

Russo, D., Jury, W.A., and Butters, G.L. 1989. Numerical analysis of solute transport during transient irrigation: 1. The effect of hysteresis and profile heterogeneity. Water Resources Research, 25(10): 2109-2118.

Scott, P., Farquhar, G., and Kouwen, N. 1983. Hysteretic effects on net infiltration. In Advances in infiltration. American Society of Agricultural Engineers Publication 11-83, St. Joseph, Michigan, pp 163-170.

Šimůnek, J., Šejna, M., Saito, H., Sakai, M., and van Genuchten, M.Th. 2013. The Hydrus-1D Software Package for Simulating the Movement of Water, Heat, and Multiple Solutes in Variably Saturated Media, Version 4.17. Hydrus Software Series 3, Department of Environmental Sciences, University of California Riverside, Riverside, California, USA, 342 pages.

Stauffer, F. and Dracos, T. 1984. Local infiltration into layered soils and response of the water table, experiment and simulation. In Frontiers in Hydrology, (W. Maxwell and L. Beard, eds.) pp 228242. Water Res. Publ. Littleton, Colorado.

Stephens, D.B. 1996. Vadose Zone Hydrology. CRC Press Inc., Boca Raton, FL, USA. 
Thornthwaite, C.W. 1948. An approach toward a rational classification of climate. Geographical Review, 38: 55-94.

Thornthwaite, C.W., and Hare, F.K. 1955. Climatic Classification in Forestry. Unasylva, 9: 50-59. van Genuchten, M. Th. 1980. A closed-form equation for predicting the hydraulic conductivity of unsaturated soils. Soil Sci. Soc. Am. J. 44:892-898.

Vanderborght, J., Graf, A., Steenpass, C., Scharnagl, B., Prolingheuer, N., Herbst, M., Franssen, H.-J., and Vereecken, H. 2010. Within-Field Variability of Bare Soil Evaporation Derived from Eddy Covariance Measurements Special Section: Patterns. Vadose Zone Journal 9 (4): 943.

Vardon PJ 2014. Climatic influence on geotechnical infrastructure: a review. Environmental Geotechnics. DOI: 10.1680/envgeo.13.00055

Viaene, P., Vereecken, H., Diels, J., and Feyen, J. 1994. A statistical analysis of six hysteresis models for the moisture retention characteristic. Soil Science, 157(6): 345-355.

Werner, A. D. and Lockington, D. A. 2006. Artificial pumping errors in the Kool-Parker scaling model of soil moisture hysteresis. Journal of Hydrology, 325(1-4):118 -133.

Yang, H., Rahardjo, H., Leong, E.C., and Fredlund, D.G. 2004. A study of infiltration on three sand capillary barriers. Canadian Geotechnical Journal, 41(4): 629-643. 


\section{List of Table Captions}

Table 1: Salient characteristics of the four climatic conditions modelled in the present study

Table 2: The van Genuchten (1980) parameters for the three soils modelled in the present study

\section{List of Figure Captions}

Figure 1: Summer moisture index (SMI) values for the natural regions and sub-regions for the province of Alberta (from Natural Regions Committee 2006)

Figure 2: Yearly variations in Thornthwaite Moisture Index $\left(I_{m}\right)$ values for the four selected regions of the Canadian province of Alberta

Figure 3: The hysteretic soil-water characteristic curves (SWCC) for the three soils (labelled Soil 1, Soil 2 and Soil 3) modelled in the present study

Figure 4: Daily precipitation, daily potential evaporation, and predicted cumulative water balance for the hysteretic (HC) and non-hysteretic (DC and WC) simulations for Soil 1 with dry climatic conditions

Figure 5: Temporal distributions of the difference between precipitation and potential evaporation (P-PE), cumulative surface runoff $(R O)$ and volumetric water content $\theta$ for the hysteretic $(\mathrm{HC})$ and non-hysteretic (DC and WC) simulations for Soil 1 under dry climatic conditions

Figure 6: Temporal changes in the storage in Soil 1 under dry climatic conditions for the hysteretic (HC) and non-hysteretic (DC and WC) simulations

Figure 7: Driest and wettest water content profiles for Soi1 1 under dry climatic conditions predicted by the hysteretic (HC) and the non-hysteretic (DC and WC) simulations

Figure 8: Predicted cumulative values of actual evaporation $(A E)$, net infiltration $(N I)$, surface runoff $(R O)$ and bottom flux $(B F)$ for Soil 1 under four different climatic conditions from hysteretic (HC) and non-hysteretic (DC and WC) simulations 
Figure 9: Predicted cumulative values of actual evaporation $(A E)$ and net infiltration $(N I)$ for the three soils (Soil 1, Soil 2 and Soil 3) under four different climatic conditions from hysteretic (HC) and non-hysteretic (DC and WC) simulations

Figure 10: Paired water content-suction data points for the top node for the HC, DC and WC simulations for Soil 2, superimposed on the hysteretic SWCC for Soil 2

Figure 11: Switching of the hysteresis index $(\kappa)$ in Hydrus-1D with the moisture content time history at three different spatial locations for a part of the HC (hysteretic) simulation for Soil : (a) at the ground surface; (b) at $0.5 \mathrm{~m}$ depth; (c) at $1.0 \mathrm{~m}$ depth

Figure 12: Daily precipitation, daily potential evaporation, and predicted cumulative water balance for the hysteretic (HC) and non-hysteretic (DC and WC) simulations for Soil 2 with increased precipitation intensity 


\section{Tables}

Table 1: Salient characteristics of the four climatic conditions modelled in the present study

\begin{tabular}{lcccc}
\hline Climate & Very Dry & Dry & Wet & Neutral \\
\hline Period & $1996-1999$ & $2004-2008$ & $1965-1969$ & $2003-2008$ \\
Number of years & 4 & 5 & 5 & 5 \\
Active days per year & 212 & 201 & 202 & 193 \\
Cumulative precipitation (mm) & 774 & 1698 & 2324 & 1920 \\
Averaged cumulative precipitation per & 194 & 340 & 465 & 384 \\
year (mm) & & & & \\
Cumulative potential evaporation (mm) & 1830 & 2710 & 1798 & 3803 \\
Averaged cumulative potential & 458 & 542 & 360 & \\
evaporation per year (mm) & & & & \\
1955Thornthwaite Moisture Index $\left(I_{m}\right)$ & -64.1 & -46.8 & 11.9 & -13.9 \\
\hline
\end{tabular}


Table 2: The van Genuchten (1980) parameters for the three soils modelled in the present study

\begin{tabular}{lccc}
\hline Soil ID & Soil 1 (Loam) & Soil 2 & Soil 3 \\
Description & Loam & Silty sand & Silty loam \\
\hline$\theta_{r}[-]$ & 0.21 & 0.07 & 0.03 \\
$\theta_{s}[-]$ & 0.52 & 0.38 & 0.4 \\
$n[-]$ & 1.704 & 2.02 & 1.228 \\
$K_{s}[\mathrm{~mm} / \mathrm{d}]$ & 19.15 & 259.2 & 1373 \\
$\alpha^{d}[1 / \mathrm{mm}]$ & 0.0015 & 0.002 & 0.0091 \\
$\alpha^{w}[1 / \mathrm{mm}]$ & 0.008 & 0.003 & 0.0503 \\
\hline
\end{tabular}

$\overline{\text { [Note: } \theta_{r}-\text { residual volumetric water content; } \theta_{s}-\text { saturation volume }}$ tric water content; $K_{s}$ saturated hydraulic conductivity; $n, \alpha^{d}$ and $\alpha^{w}$ - van Genuchten (1980) parameters.] 


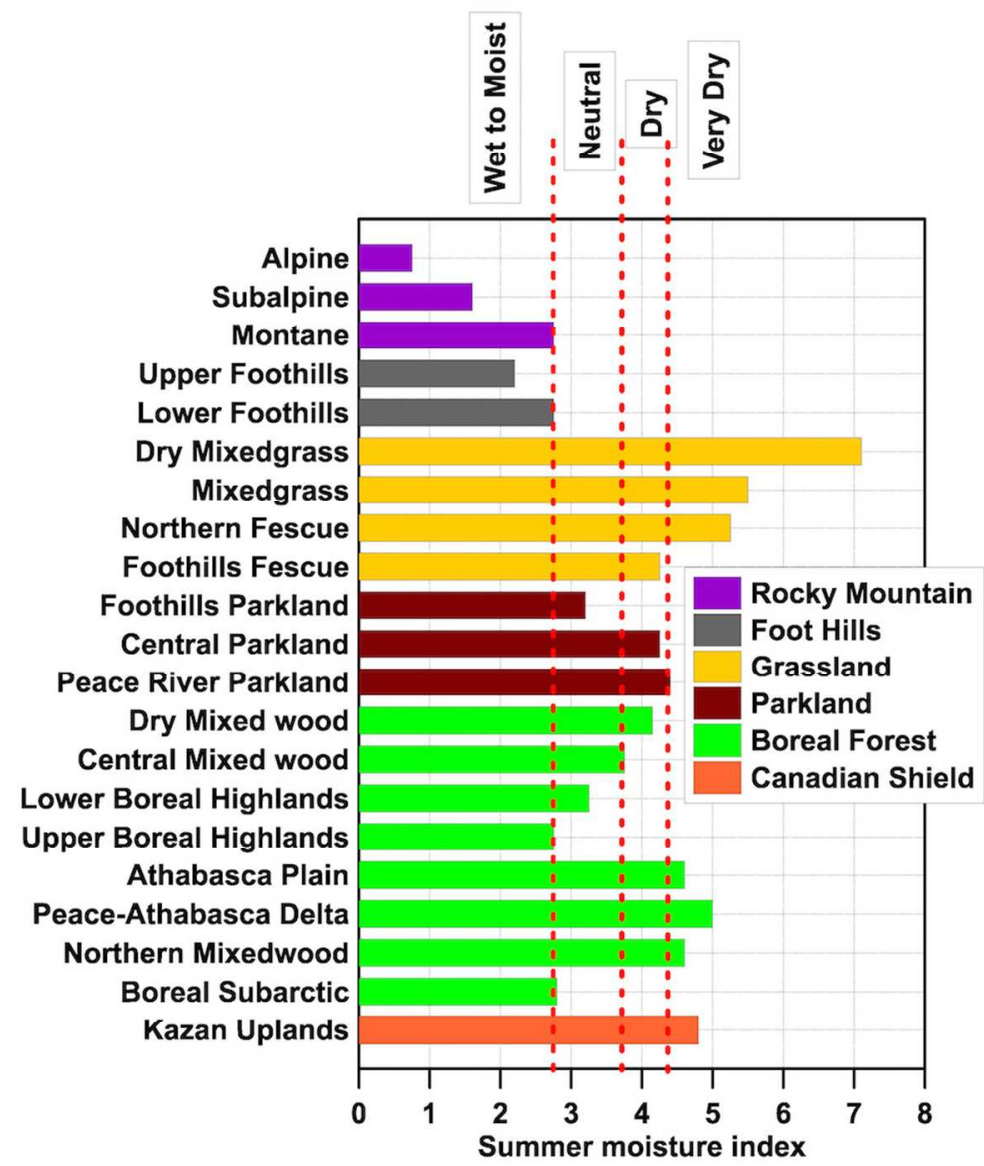

Figure 1: Summer moisture index (SMI) values for the natural regions and sub-regions for the province of Alberta (from Natural Regions Committee 2006)

$$
86 \times 132 \mathrm{~mm}(300 \times 300 \mathrm{DPI})
$$




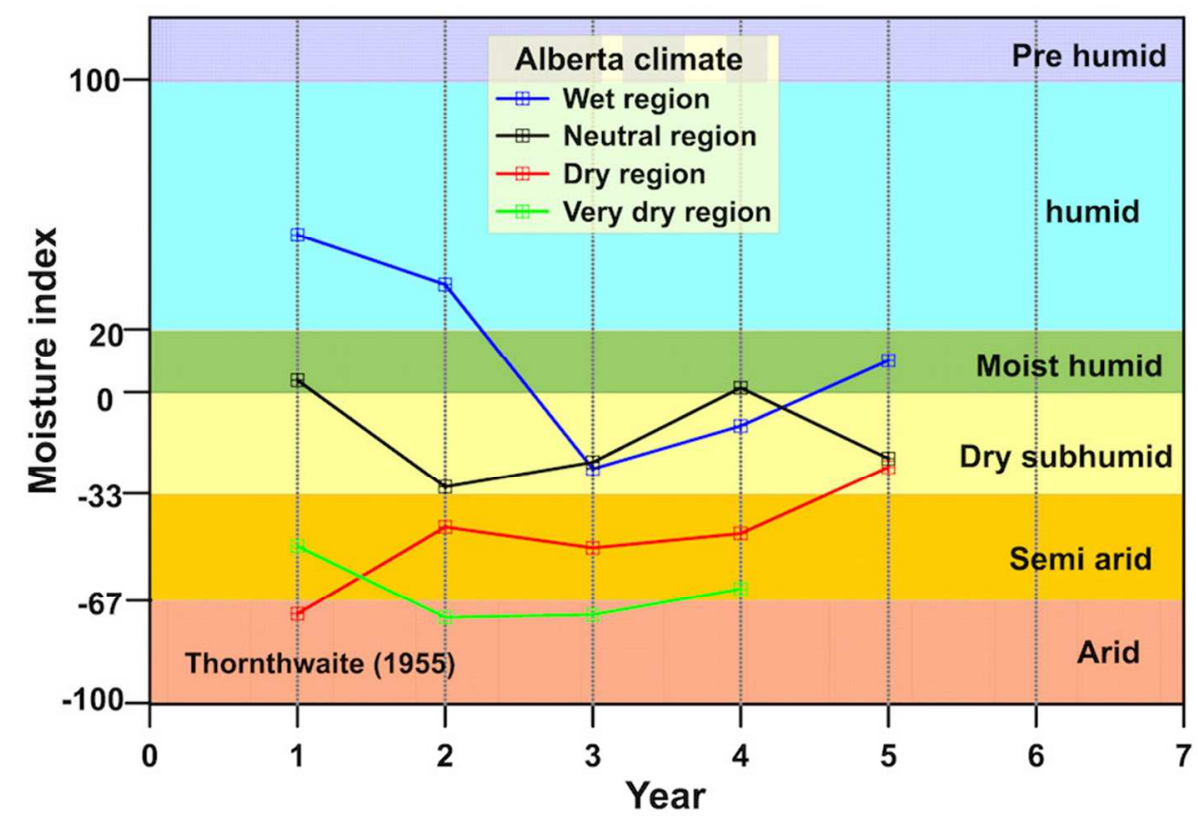

Figure 2: Yearly variations in Thornthwaite Moisture Index (Im) values for the four selected regions of the Canadian province of Alberta $86 \times 55 \mathrm{~mm}(300 \times 300 \mathrm{DPI})$ 


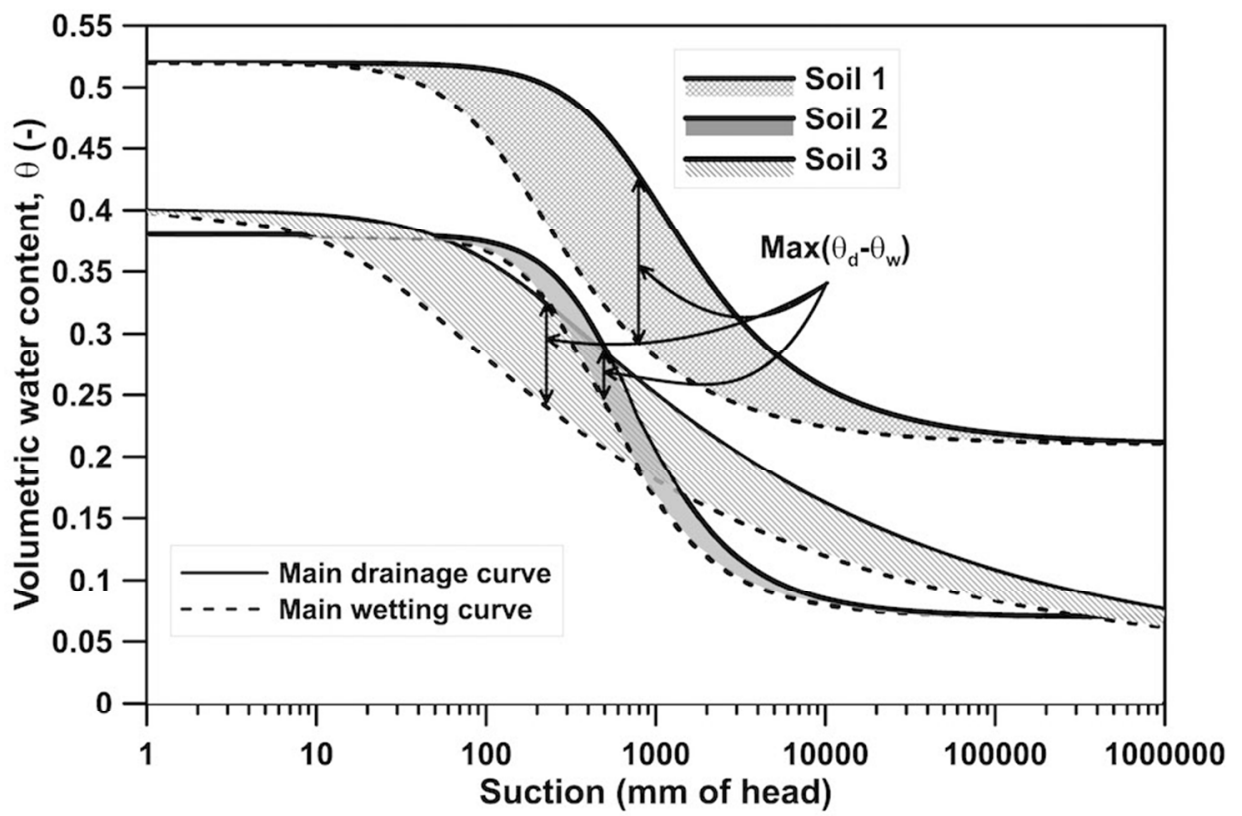

Figure 3: The hysteretic soil-water characteristic curves (SWCC) for the three soils (labelled Soil 1 , Soil 2 and Soil 3) modelled in the present study $86 \times 55 \mathrm{~mm}(300 \times 300$ DPI $)$ 


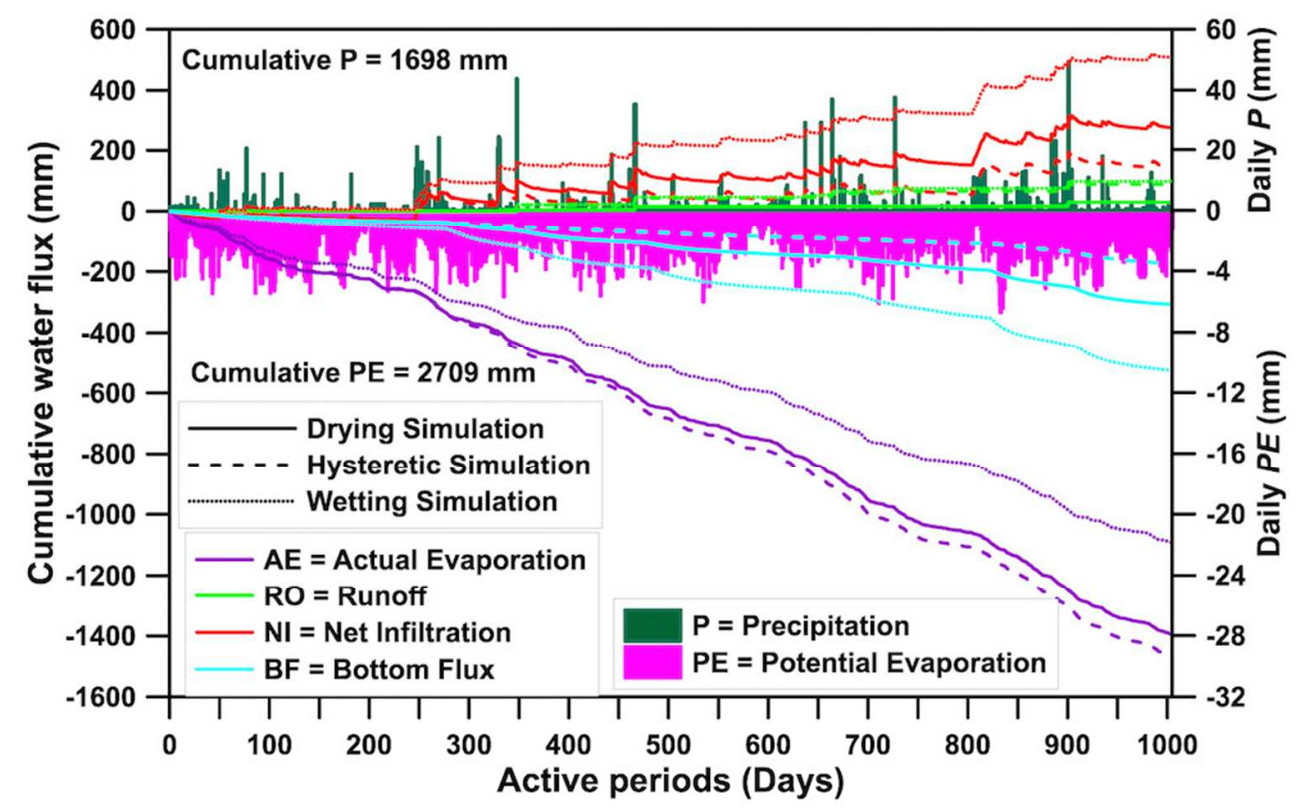

Figure 4: Daily precipitation, daily potential evaporation, and predicted cumulative water balance for the hysteretic (HC) and non-hysteretic (DC and WC) simulations for Soil 1 with dry climatic conditions $86 \times 55 \mathrm{~mm}(300 \times 300 \mathrm{DPI})$ 


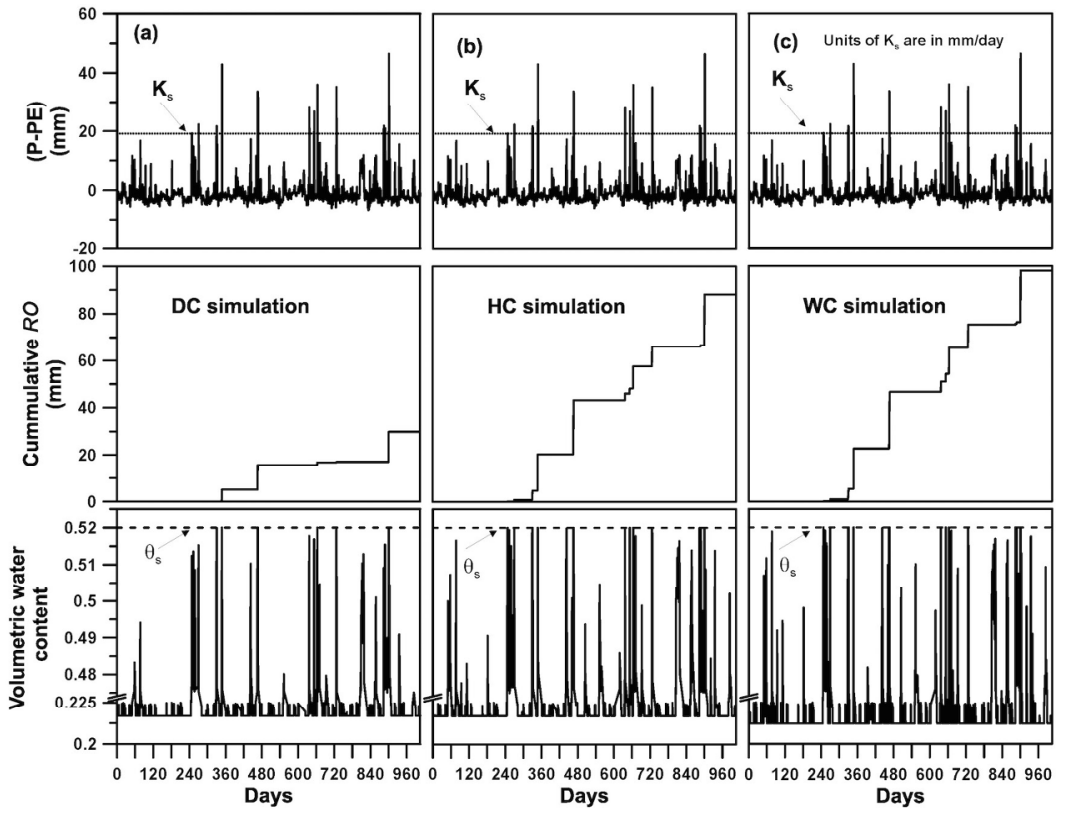

Figure 5: Temporal distributions of the difference between precipitation and potential evaporation (P-PE), cumulative surface runoff (RO) and volumetric water content $\theta$ for the hysteretic $(\mathrm{HC})$ and non-hysteretic (DC and WC) simulations for Soil 1 under dry climatic conditions $182 \times 117 \mathrm{~mm}(300 \times 300 \mathrm{DPI})$ 


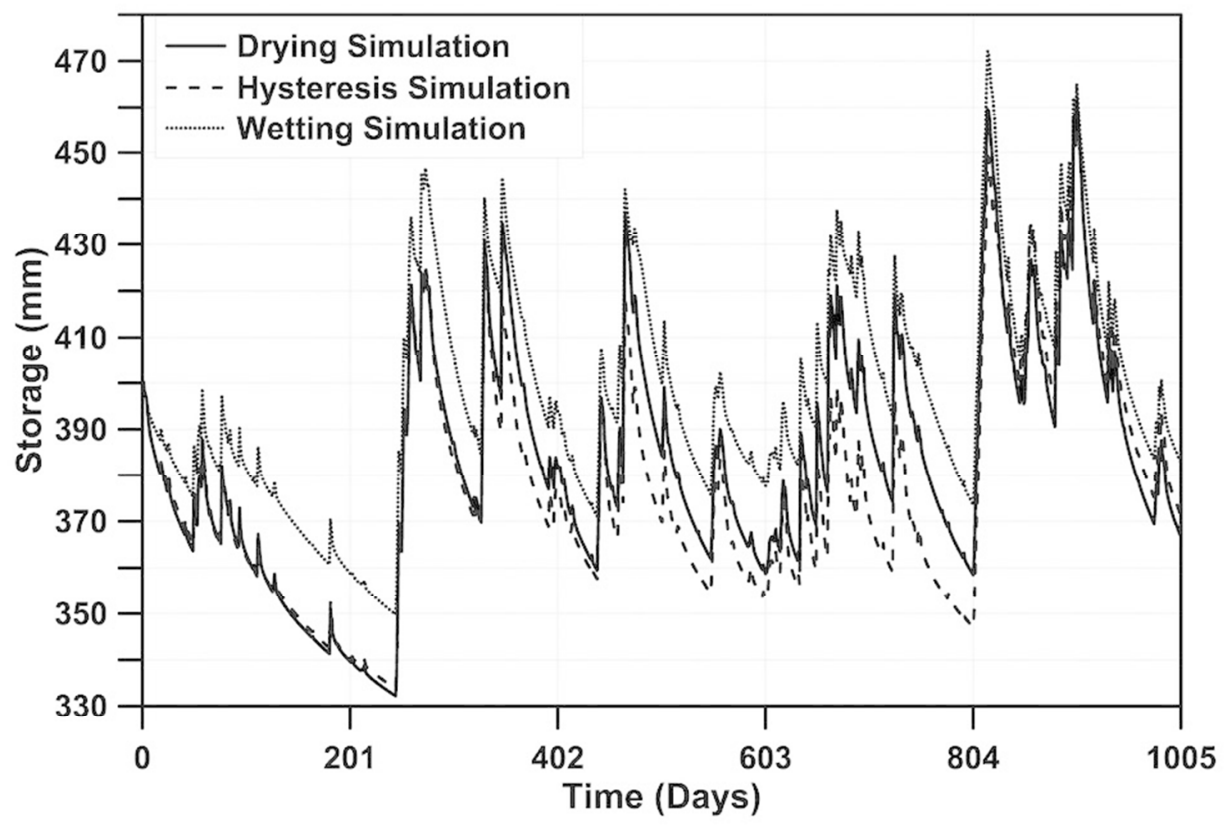

Figure 6: Temporal changes in the storage in Soil 1 under dry climatic conditions for the hysteretic (HC) and non-hysteretic (DC and WC) simulations $86 \times 55 \mathrm{~mm}(300 \times 300 \mathrm{DPI})$ 


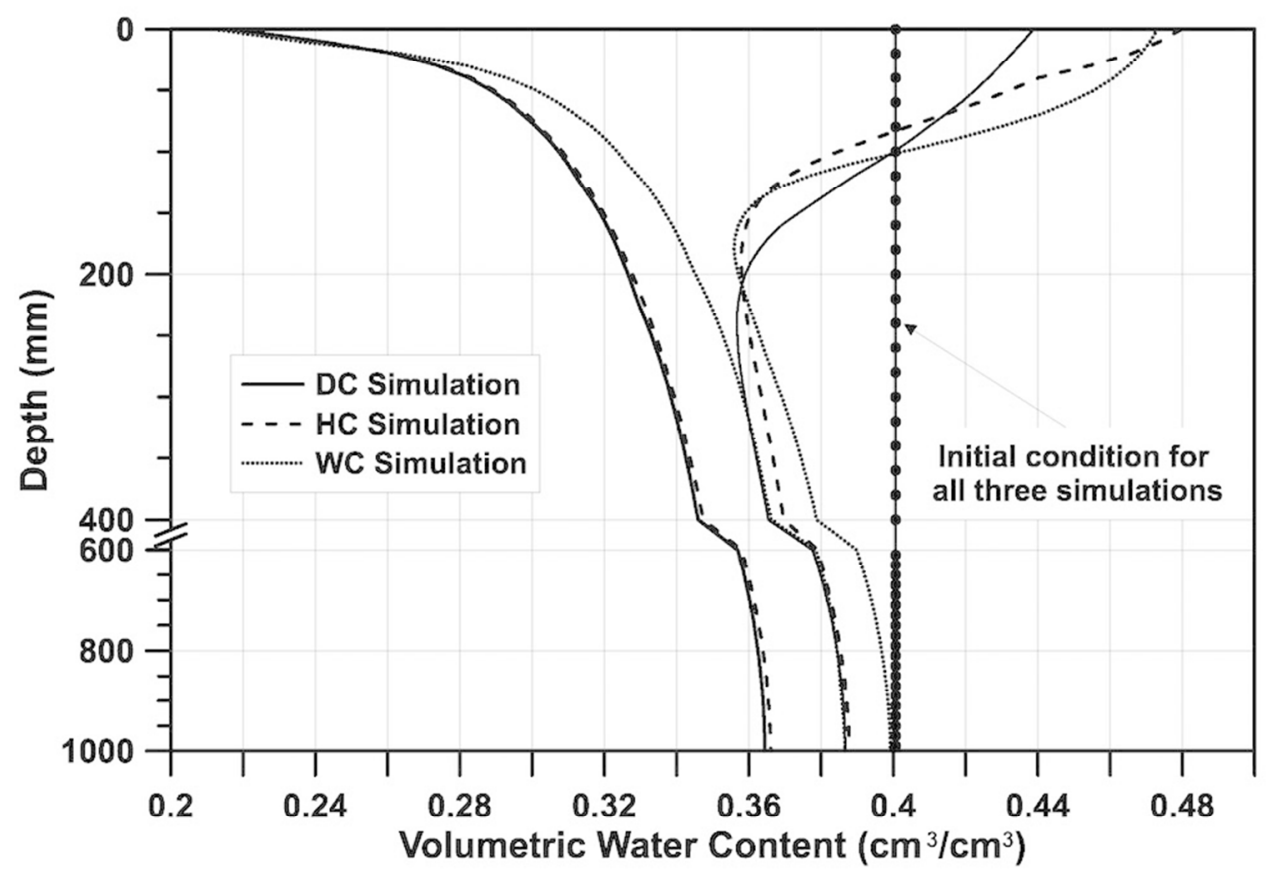

Figure 7: Driest and wettest water content profiles for Soi 11 under dry climatic conditions predicted by the hysteretic (HC) and the non-hysteretic (DC and WC) simulations

$86 \times 66 \mathrm{~mm}(300 \times 300 \mathrm{DPI})$ 

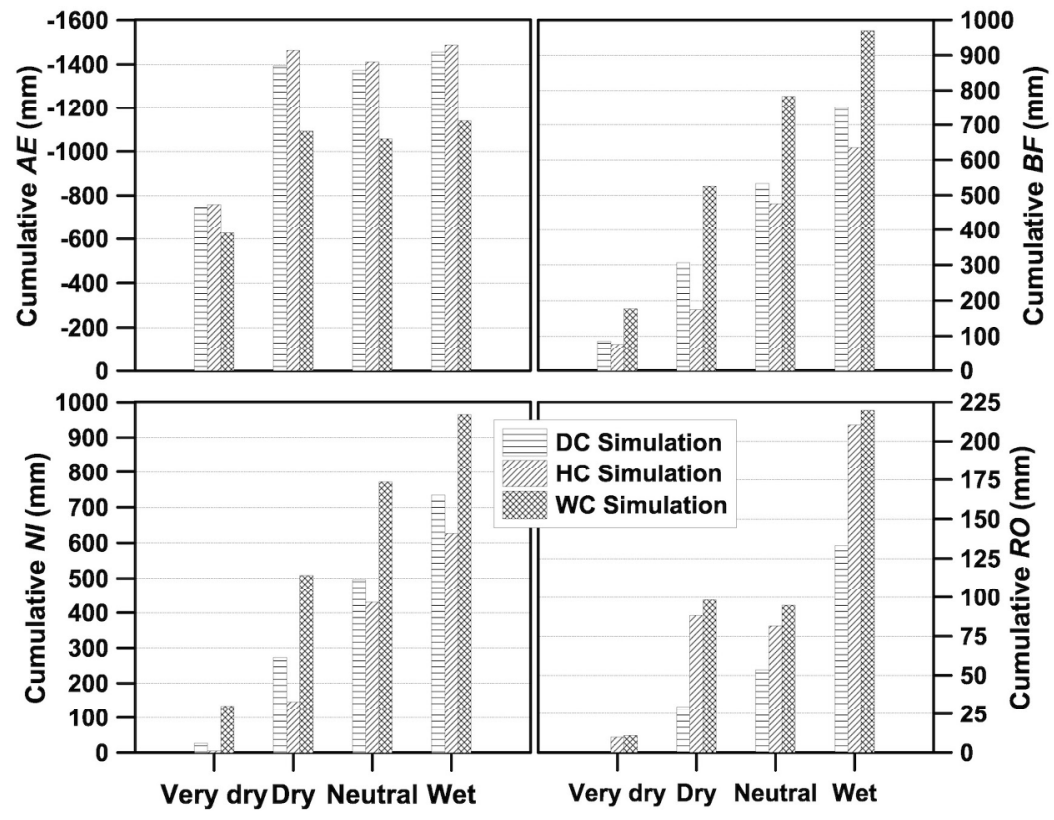

Figure 8: Predicted cumulative values of actual evaporation (AE), net infiltration (NI), surface runoff (RO) and bottom flux (BF) for Soil 1 under four different climatic conditions from hysteretic (HC) and nonhysteretic (DC and WC) simulations $182 \times 117 \mathrm{~mm}(300 \times 300 \mathrm{DPI})$ 

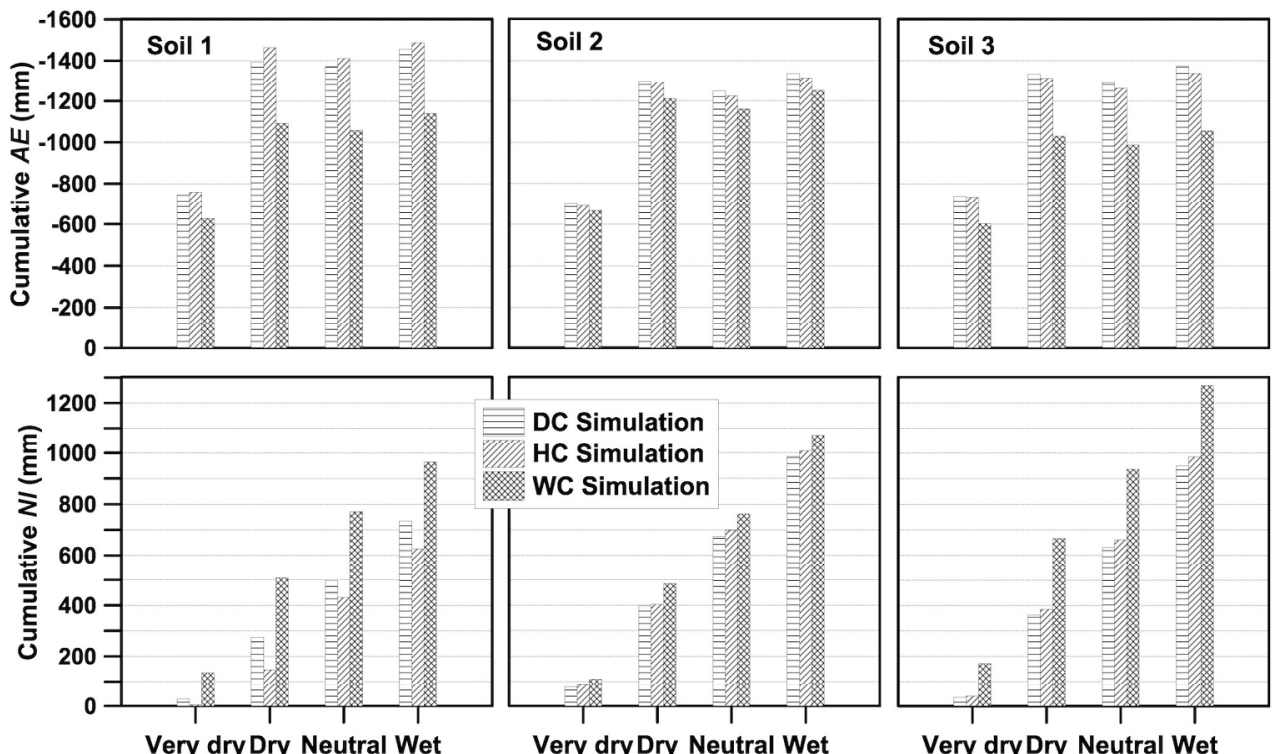

Very dry Dry Neutral Wet

Figure 9: Predicted cumulative values of actual evaporation (AE) and net infiltration (NI) for the three soils (Soil 1, Soil 2 and Soil 3) under four different climatic conditions from hysteretic (HC) and non-hysteretic (DC and WC) simulations $182 \times 117 \mathrm{~mm}(300 \times 300 \mathrm{DPI})$ 


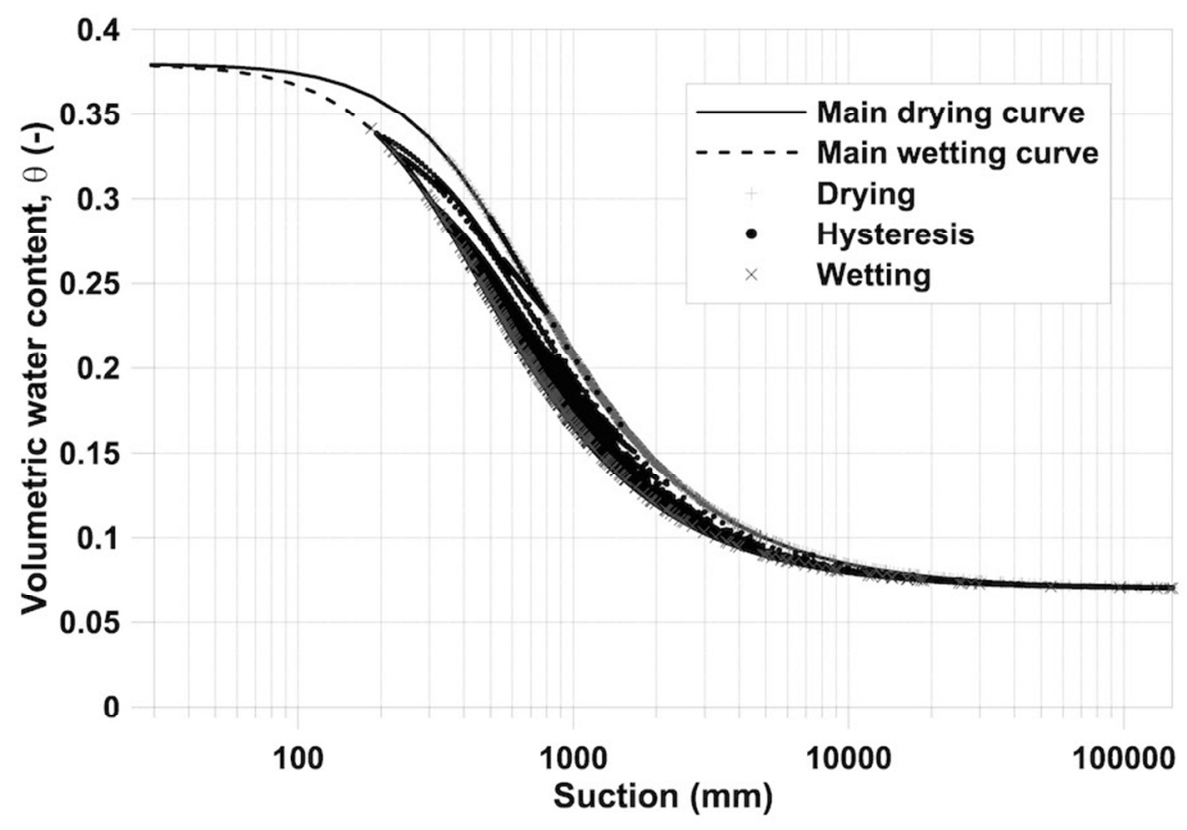

Figure 10: Paired water content-suction data points for the top node for the HC, DC and WC simulations for Soil 2, superimposed on the hysteretic SWCC for Soil 2 $86 \times 55 \mathrm{~mm}(300 \times 300$ DPI $)$ 

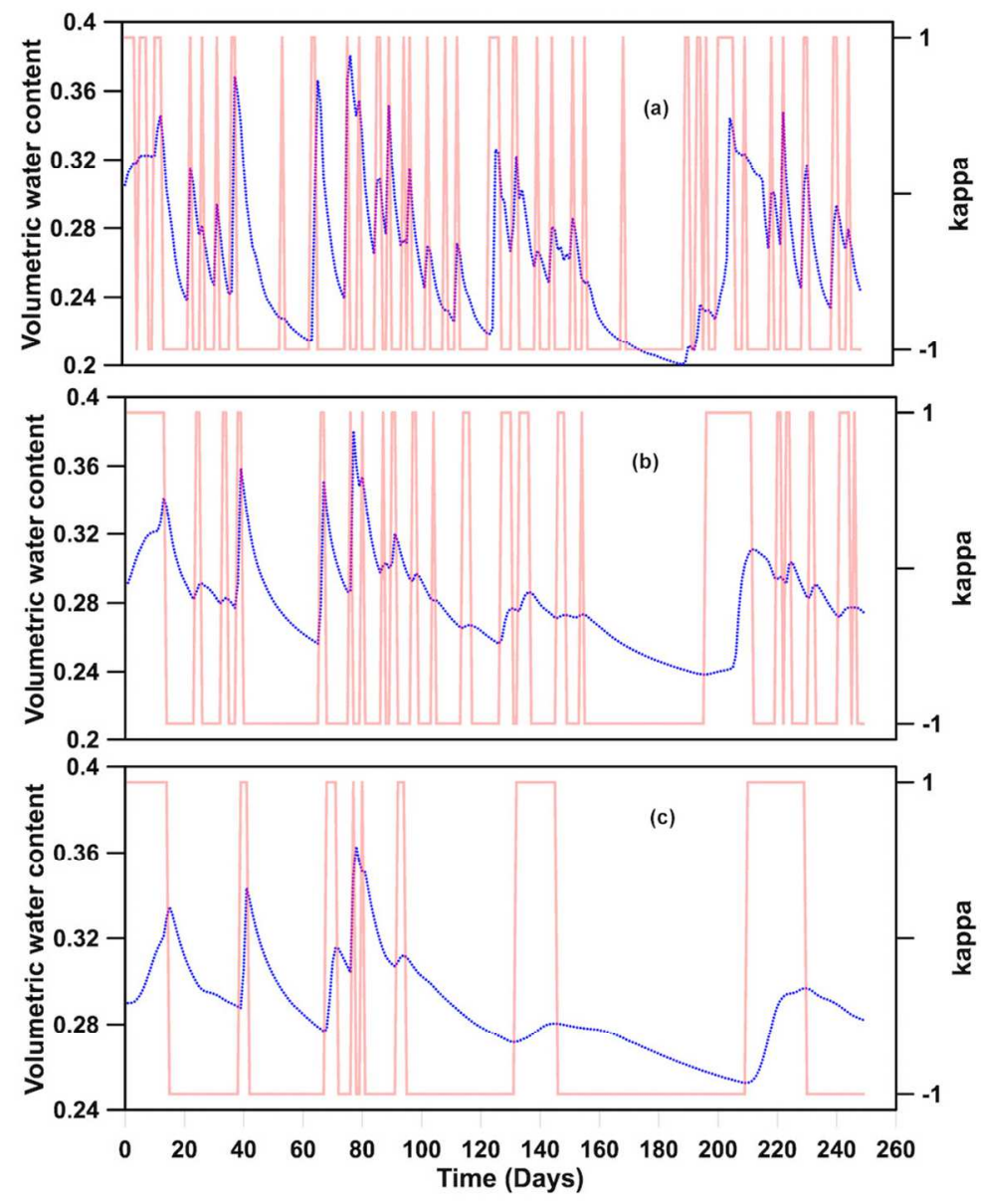

Figure 11: Switching of the hysteresis index $(\kappa)$ in Hydrus-1D with the moisture content time history at three different spatial locations for a part of the HC (hysteretic) simulation for Soil : (a) at the ground surface; (b) at $0.5 \mathrm{~m}$ depth; (c) at $1.0 \mathrm{~m}$ depth

$86 \times 132 \mathrm{~mm}(300 \times 300 \mathrm{DPI})$ 


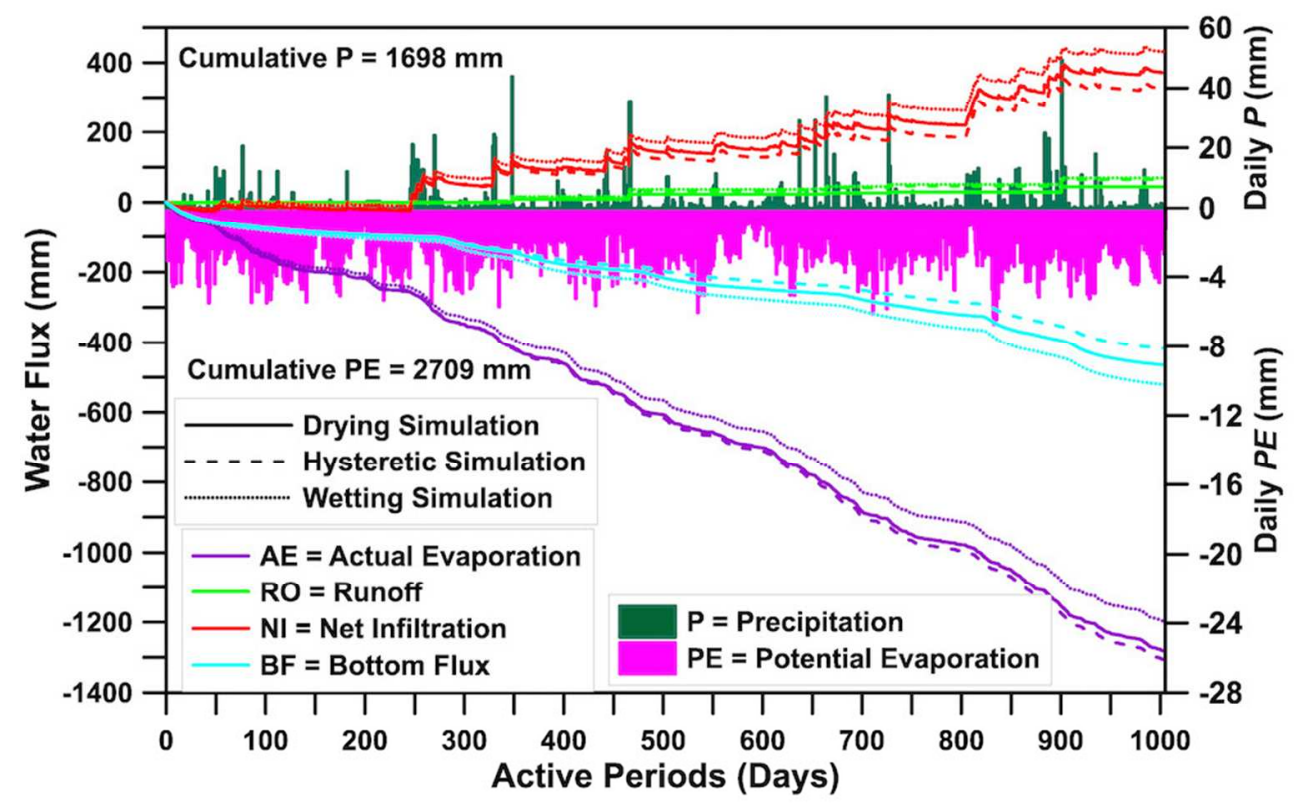

Figure 12: Daily precipitation, daily potential evaporation, and predicted cumulative water balance for the hysteretic (HC) and non-hysteretic (DC and WC) simulations for Soil 2 with increased precipitation intensity $86 \times 55 \mathrm{~mm}(300 \times 300 \mathrm{DPI})$ 